\title{
PERCEPÇÕES LOCAIS DO PATRIMÔNIO: A ESCOLA SENAC DE MARILIA.
}

\author{
Rodrigo Modesto Nascimento \\ Licenciado e Mestre em História pela Unesp, Doutor em História pela PUC/SP. \\ Professor Titular na Unip, PEB II na Secretaria de Estado da Educação de São Paulo, \\ no Programa Ensino Integral - PEl e tutor a distância na Univesp. \\ rodrigo.modesto@hotmail.com
}

resumo: A proposta deste artigo é analisar e compreender a apropriação, pela sociedade local, de um tombamento realizado pelo Condephaat (Conselho de Defesa do Patrimônio Histórico, Arqueológico, Artístico e Turístico), em 2005, da Escola SENAC, na cidade de Marília, situada no Oeste Paulista.

Palauras-chave: Patrimônio cultural; Marília-SP; arquitetura moderna. abstract: The proposal of this article is to analyze and understand the appropriation, by the local society, of a tally made by Condephaat (Council for the Defense of Historical, Archaeological, Artistic and Tourist Heritage), in 2005, of the SENAC School, in the city of Marília, West Paulista.

Key-words: Cultural heritage; Marília-SP; modern architecture. 


\section{marília e a escola senac}

No picadão aberto pela Comissão Geográfica e Geológica do Estado, em 1905, entre os rios Peixe e Feio, se localiza uma das franjas pioneiras mais prósperas da terra paulista. Nela, Marília fígurou como cidade-referência da transformação do espaço do cafezal para aquele do comércio e da indústria1.

(9)

Município de Marília está localizado no Oeste Paulista (Figura 01), possui uma população de aproximadamente 235 mil habitantes, estimada pelo IBGE para o ano de 2017. Marília é referência para toda essa região, tanto nos setores de comércio e serviços, e, em especial, o setor industrial, bem como na área educacional, com a presença de duas grandes universidades, a UNESP e a UNIMAR.

Em 1913, o governo do Estado de São Paulo determinou a construção de uma estrada ligando o atual município de Cafelândia a Platina e, com isso, muitos imigrantes (japoneses, italianos, sírios, entre outros) e migrantes de outras regiões do Estado, e, mineiros, chegaram a essa região inicialmente para plantar café, depois, o algodão. Bento de Abreu Sampaio Vidal, natural de São Carlos, no ano de 1926. cedeu terras a Cia. Paulista de Estradas de Ferro e, em 1928, inaugurou-se a estação ferroviária com o nome de Marília².

\footnotetext{
1 MARTINS, Ana Luiza. Interior paulista: comércio, indústria e bancos. In: SETUBAL, Maria Alice. (Org.). Terra paulista: trajetórias contemporâneas. SP: IMESP; CENPEC, 2008, p. 49-77, p. 69.
}

${ }^{2}$ IBGE. Marília. Disponível: https: //cidades.ibge.gov.br/brasil/sp/marilia/historico. Acesso: 15 dez. 2017. 


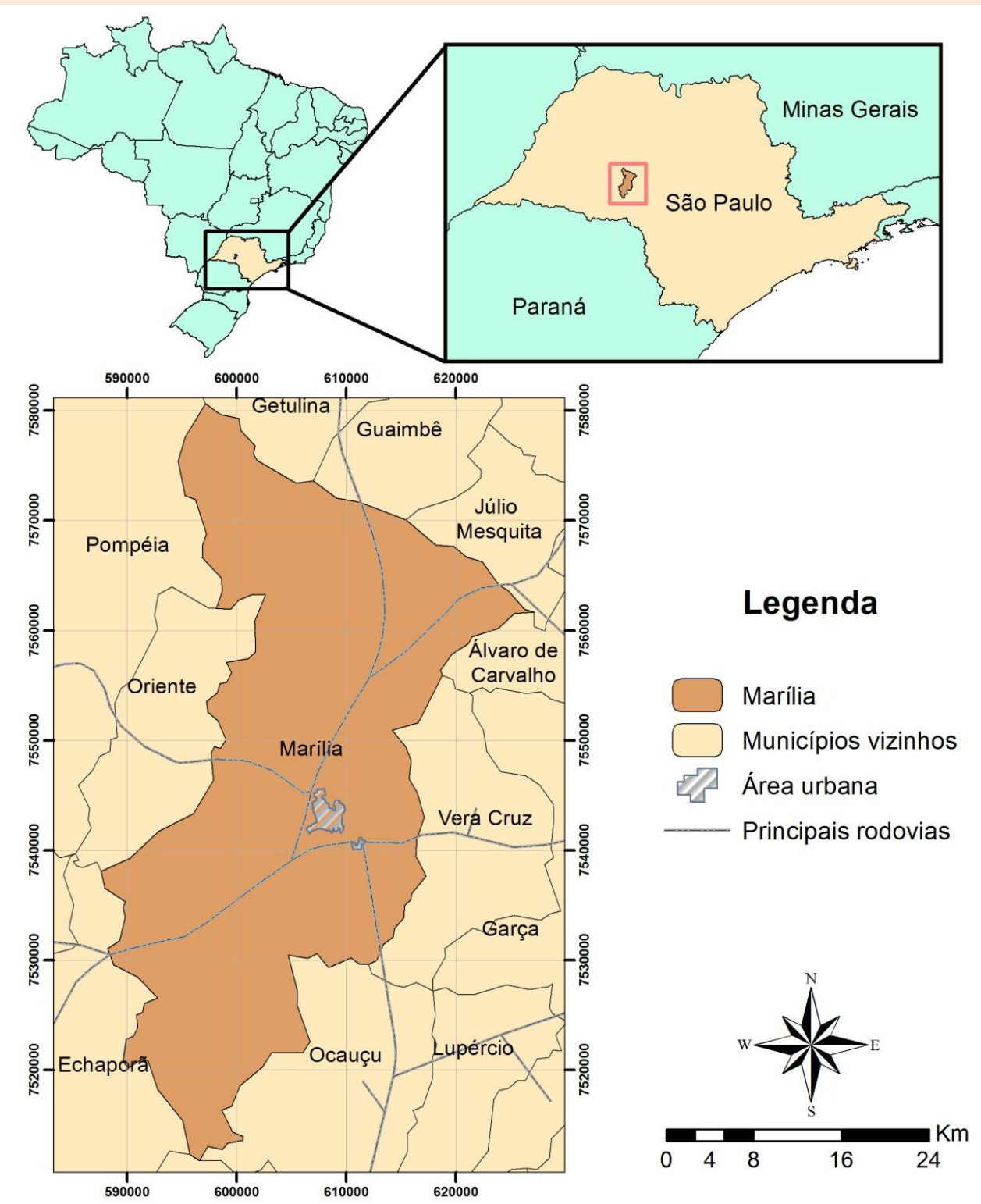

Figura 01: Mapa de localização do município de Marília, no interior paulista. Autora: Ana Maria Amaral, 2014.

\section{De acordo com Áureo Busetto:}

(...) no período 1940-1964, define-se como município ligado a agricultura, porém apresentando uma diversificação de culturas e um distrito-sede urbanizado, num processo rápido e constante. Da mesma forma observou-se a formação na localidade de um centro industrial e comercial de interesse para toda uma região ${ }^{3}$.

\footnotetext{
3 BUSETTO, Áureo. Economia e poder local: Marília de 1946 a 1964. Dissertação (Mestrado em História). Assis: UNESP, 1991, p. 64.
} 
Devido ao crescimento industrial e comercial, verificado na citação acima, surgiu à necessidade de qualificar mão de obra especializada para a indústria e o comércio de Marília. Assim, em finais da década de 1950, o SESC-SENAC iniciou a construção de uma unidade em Marília que seguiu os princípios da arquitetura moderna.

O prédio da Escola SESC-SENAC de Marília, a segunda unidade projetada no Estado de São Paulo, em 1955, pelos arquitetos Oswaldo Correia Gonçalves, Rubens Carneiro Vianna e Ricardo Siervers, foi inaugurado em doze de abril de 1958. Dividido em dois blocos, e, desde 1971, o SENAC adquiriu parte do SESC, sendo conhecido atualmente pelo penúltimo nome.

Os arquitetos Nilson Ghiraldello e Alfredo Ramos, afirmam que:

$O$ edifício se insere na cidade em um contexto urbano ainda em formação. A cidade (..) está em pleno desenvolvimento e localizada em um ponto estratégico no estado que de forma bastante célere interiorizava a industrialização. Respondendo a tais demandas da indústria e também do comércio, o sistema "S" potencializa a formação de seus trabalhadores4.

É importante frisar que o Serviço Nacional de Aprendizagem Comercial (SENAC) faz parte do chamado sistema "S" (SENAI, SEST, entre outros) criado pela Confederação Nacional do Comércio, em 10 de janeiro de 1946. A principal finalidade dessa instituição é a Educação Profissional, preparando seus alunos para as diversas atividades técnicas e comerciais 5 .

\section{o tombamento}

A palavra patrimônio origina-se da palavra grega pater, que significa "pai", portanto, relaciona-se com a ideia de herança. Com o passar do tempo, patrimônio passou a ser utilizado para designar bens materiais, e, também, imateriais, considerados vetores para a memória e a identidade das diferentes sociedades.

${ }^{4}$ GHIRARDELLO, Nilson; RAMOS, Alfredo Zaia Nogueira. Crescimento urbano e modernismo em Marília. In: Anais do $4^{\circ}$ Seminário Ibero-americano. BH: Editora da UFMG, 2015, p. 12.

${ }^{5}$ Disponível: www.senac.br. Acesso em: 15 mar. 2012. 
A Escola SENAC de Marília foi inscrita no Livro do Tombo Histórico do Condephaat em 2005 após um longo e acalorado debate entre o órgão paulista de preservação e a Direção da instituição, que não queria ver seu imóvel tombado. É importante salientar que existem poucos exemplares vinculados ao Movimento Moderno protegidos oficialmente em âmbito estadual:

Não chega a trinta o número de edificações vinculadas à arquitetura do Movimento Moderno dentre os mais 500 bens tombados pelo Condephaat, órgão de preservação do patrimônio cultural do estado de São Paulo. Levando-se em conta ainda seus mais de 45 anos de existência, vê-se que é um nứmero pequeno 6 .

O pedido de tombamento da Escola SENAC de Marília ao órgão paulista de patrimônio cultural partiu do Instituto dos Arquitetos do Brasil (IAB-SP), entidade classista sediada na capital paulista, em 19 de junho de 1990, pelo então Presidente na época, o arquiteto Pedro Antônio Galvão Cury?

A preservação desse edifício, na solicitação, circunscreveu-se na valorização arquitetura moderna:

Inaugurado em 12 de abril de 1958, o edifício projetado pelo arquiteto Oswaldo Correia Gonçalves é exemplar representativo da arquitetura moderna paulista, baseada nos princípios do funcionalismo e racionalismo de Le Corbusier. Ocupando uma área útil de 646 metros quadrados, distribuídos em dois pavimentos, destina-se o térreo ao Centro Social do SESC e, o superior, à Escola SENAC. Destacam-se na edificação, além da cobertura de laje plana, sem telhado, a movimentação dos espaços com a criação de pátios e jardins e ladrilhos hidráulicos e a caixilharia, todos característicos da nova maneira de projetar ${ }^{8}$.

${ }^{6}$ WOLFF, Sílvia Ferreira Santos; ZAGATO, José Antônio Chinelato. A preservação do patrimônio moderno no Estado de São Paulo pelo Condephaat. Arquitextos (São Paulo), v. 17, p. 1-15, 2016, p. 02.

7 Processo de Tombamento n. 27.945/90. Arquivo do Condephaat.

8 Descrição do bem tombado presente no site da Secretaria de Estado da Cultura de São Paulo. Livro do Tombo Histórico n. 347, p. 93, em 31/01/2005. Disponível: www.condephaat.sp.gov.br. Acesso: 10 jan. 2018.

NASCFMETO, Kodrieno Modesto. Fercepções loçais do patrimônio: a Escola SENAC de Marílía. albuquerque: revista de história. val. 10, no 19. jan.-jul. de 2018. p. $146-160$. 
Egrégio Colegiado do Condephaat em 1990 delíberou a favor da abertura de estudos sobre a Escola SENAC. Com isso, a historiadora do STCR (Serviço Técnico de Conservação e Restauro), Ana Luiza Martins em parecer enviado para a Diretoria Técnica, explanou:

No panorama das obras anunciadas naquele momento, quais seja Prefeitura Municipal, Colégio Cristo Reí, Educandário Bezerra de Meneses, destacava-se o projeto do SENAC, distante dos demais na proposta plástica, porém afinado com a melhor arquitetura que se produzia no país $(. . .)^{9}$.

Nesse documento a autora ressaltou o valor estético desse prédio, relacionado ao princípio da arquitetura modernista, no interior paulista, frente às outras edifícações, construídas em fins dos anos 1950 e importância da sua preservação como patrimônio cultural paulista.

Em seguida, o arquiteto Nilson Ghirardello, conselheiro do Condephaat, representante da UNESP, Campus Bauru, em 23 de março de 1995, manifestou intenção favorável ao tombamento da Escola SENAC em Marília, baseado nos estudos realizados pela historiadora do STCR, reproduzido na citação acima.

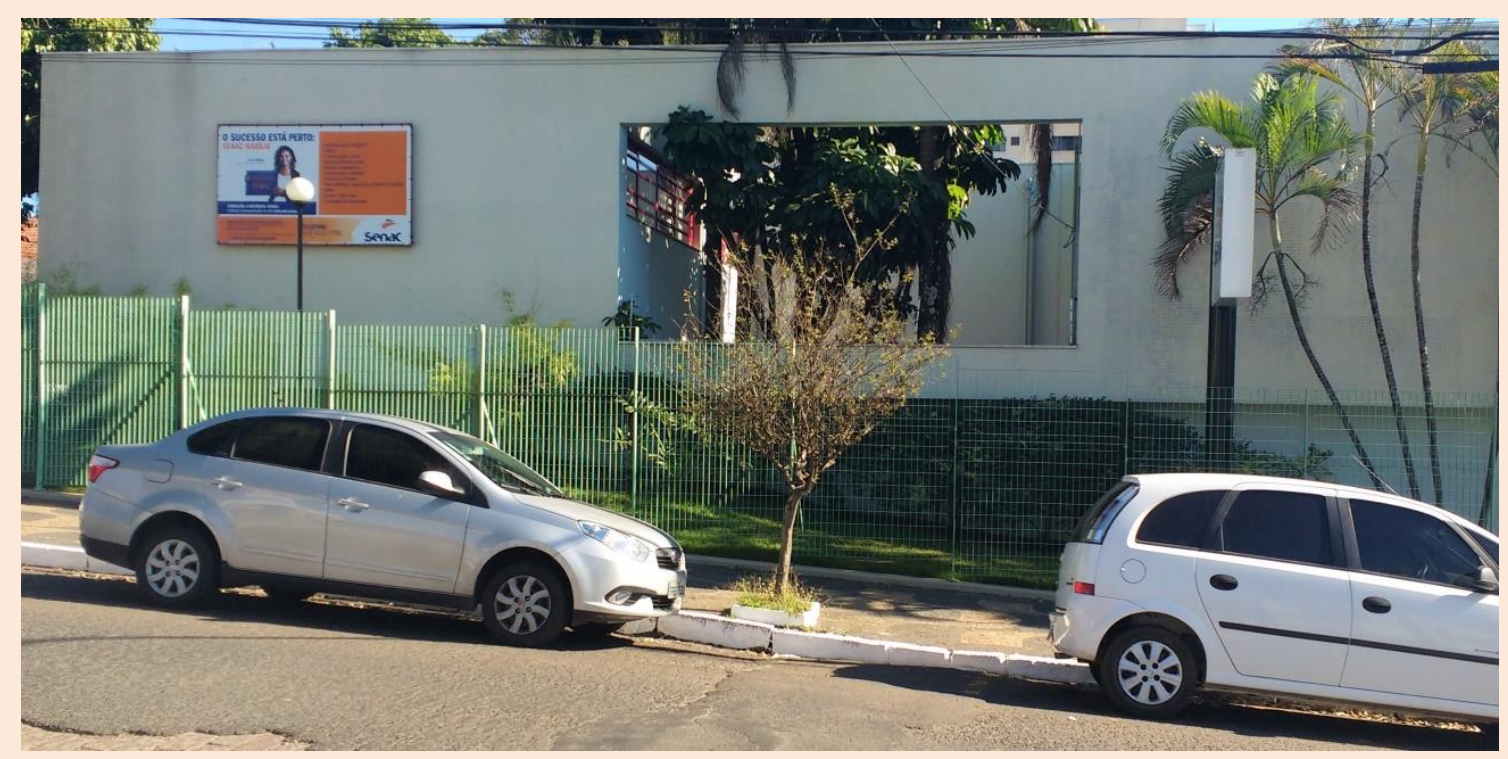

Figura 02: Detalhe do corte retangular da fachada da Rua Paraíba. Autor: Rodrigo Modesto Nascimento, 2016.

\footnotetext{
${ }^{9}$ Processo de Tombamento n. 27.945/90, p. 195.
} 
Assim, o pedido de proteção oficial foi aceito pelos conselheiros em reunião do Egrégio Colegiado. É importante ressaltar que o critério primordial da proteção oficial do prédio está relacionado ao seu valor estético ou formal, isto é, na valorização dos princípios da arquitetura moderna.

Essas unidades escolares foram projetadas, segundo Artemis Rodrigues Fontana Ferraz para:

(...) atender a pedagogia em voga, vale lembrar que a linguagem utilizada para atender a esta nova concepção foí a da arquitetura moderna. Dos grandes vãos de luz natural à aplicação das artes plásticas, elementos foram compostos para despertar no aluno mais do que o ensino técnico industrial e comercial, mas sim a ampliação de horizontes necessária à formação do trabalhador ${ }^{10}$.

Durante os estudos realizados pelo órgão paulista de preservação, entre 1990 e 2004, nenhum grupo ou indivíduo da sociedade local interessou-se em participar do processo administrativo que tramitava no Condephaat, contrário ou a favor do tombamento dessa edificação. Sendo assim, não houve, por exemplo, o envio de fotografias da escola ou recortes de jornais, a realização de abaixo-assinados, entre outros documentos que demonstram os diversos interesses envolvidos nos estudos de tombamento.

$\bigcirc$ que entendemos por sociedade local? São os grupos sociais que se manifestaram nas fontes históricas produzidas em Marília em relação à Escola SENAC, interessados na história e cultura como os membros da Comissão dos Registros Históricos e da Secretaria Municipal de Cultura, grupos que se formaram no âmbito do poder público municipal.

Para finalizar os estudos sobre o tombamento da escola: quais foram os motivos da demora da decisão final do órgão paulista de preservação do patrimônio cultural? Foi devido a uma disputa jurídica, que se arrastou por longos catorze anos, entre a dirreção desse órgão, que não concordava com o tombamento e o Estado, representado pelo Condephaat, onde o Estado conseguiu impor sua ideia, protegendo oficialmente a Escola SENAC, como um ícone do Movimento Moderno no interior paulista.

${ }^{10}$ FERRAZ, Artemis Rodrigues Fontana. Arquitetura moderna das escolas "S" paulistas, 1952-1968: projetar para a formação do trabalhador. Tese (Doutorado em Arquitetura e Urbanismo). SP: USP, 2008, P. 505. 
processo terminou em 2004, com a publicação do ato de tombamento no Diário Ofícial do Estado, em 07/10/2004, e a respectiva inscrição no Livro do Tombo Histórico, em 31/01/2005.

\section{os debates locais}

A Comissão dos Registros Históricos de Marília ${ }^{11}$ reuniu-se no dia cinco de maio de 1993, e um dos assuntos presentes na pauta dessa reunião referiu-se aos estudos do tombamento do edifício escolar. Os membros da Comissão solicitaram ao Diretor da Escola SENAC, senhor Ademar Martins, informações acerca análise realizada em âmbito do Estado ${ }^{12}$

Neste item iremos utilizar as atas dessa entidade pública como fonte histórica. Nesse sentido, o uso dessa documentação, segundo Marisa V. M. Santos, no estudo do IPHAN constitui: "(...) um conjunto discursivo extremamente importante como estratégia de institucionalização do corpus discursivo (...). Elas estabelecem um discurso que possui como produtividade simbólica a capacidade de criar o real (...) $)^{13}$.

Um dos principais problemas relatados pela Comissão circunscreveu-se as dificuldades de acesso às informações do processo de tombamento da escola. Outro ponto da reunião foi à sugestão do Presidente da Comissão, Ari Resende de Souza e Silva, arquiteto, para que a professora da UNESP, campus de Marília, Yoshico Tanabe conseguisse informações sobre o estudo do edifício escolar ${ }^{14}$

Contudo, novamente, na reunião do dia 29 de junho de 1993, o senhor Paulo Correa de Lara marcou um encontro com os professores da UNESP para tratar do assunto do tombamento da escola, em ambas as reuniões, sem acesso a dados do processo administrativo do Condephaat.

${ }^{11}$ Criada pela Portaria 228/84, (...), a comissão tem o objetivo de reunir, organizar e divulgar a memória de nossa cidade. Atualmente conta com um acervo com aproximadamente 400 fitas de vídeo com depoimentos de pioneiros, jornais, revistas, fotografias, monografias, textos, documentos e livros publicados. Este rico acervo é frequentemente requisitado por estudantes e munícipes, bem como turistas que querem conhecer melhor a nossa cidade. Disponível: https://www.marilia.sp.leg.br/imprensa/noticias/03-03-2011-comissao-de-registros-historicos-dacamara-e-da-1274. Acesso: 09 fev. 2018.

${ }^{12}$ Ata n. 05/1993. É importante lembrar que a direção da escola foi contrária ao tombamento.

13 SANTOS, Marisa Veloso Motta. Nasce a Academia SPHAN. In: Revista do Patrimônio Histórico e Artístico Nacional n. 24. RJ: IPHAN, 1996, p. 82.

${ }^{14}$ Ata n. 06/1993. 
Essa universidade teve um importante papel na preservação dos bens culturais no interior do Estado, por isso, a busca de auxílio dos membros da Comissão aos professores universitários, em que muitos eram conselheiros do Condephaat representando a UNESP. Exemplo das professoras Anna Maria Martinez Correa e Maria Ângela Dincao, que tiveram importante participação na condução dos processos de tombamento do Teatro São Vicente em Assis e da Casa da Rua Dom Pedro, 87, Marília, ambos na década de 1980.

De acordo com Paulo César Garcez Marins, na análise da restauração do Solar Aguiar Vallim, Bananal, edificação tombada na década de 1970, também, pelo Condephaat, empreendida pela Associação Pró-Reforma do Sobrado, o autor apresentou os diferentes valores que estão em jogo durante os estudos de tombamento, um para o Estado e outro, para a sociedade local ${ }^{15}$.

$\bigcirc$ órgão estadual tombou o Solar pela excepcionalidade artística (estilo neoclássico) e pela vinculação do imóvel a um personagem da elite do café. A sociedade local, representada pela referida associação, sem nenhum auxílio do Estado, restaurou o Solar devido ao seu passado escolar, valorizado e reconhecido pela comunidade de Bananal:

(...). $\bigcirc$ solar dos Valim permaneceu, portanto, como um sinal contrário a nova dignidade conferida pelo tombamento, ligado simbolicamente pelo poder público estadual a um valor testemunhal que os cidadãos não reconheciam como parte significativa de suas vidas ${ }^{16}$.

Verificamos, depois da análise das atas da Comissão dos Registros Históricos, que, entre seus membros, o assunto relativo aos estudos e posterior tombamento da Escola SENAC não significou um debate acalorado e, sim, resultaram em apenas duas atas solicitando ao Condephaat e outras instituições, e, também, a professores da UNESP, o acesso às informações dos estudos de tombamento da Escola SENAC.

15 MARINS, Paulo César Garcez. Trajetórias de preservação do patrimônio cultural paulista. In: SETUBAL, Maria Alice. (Org.). Terra paulista: trajetórias contemporâneas. SP: IMESP; CENPEC, 2008, p. 237-267.

${ }^{16}$ MARINS, Paulo César Garcez. Op. Cit. p. 165. 


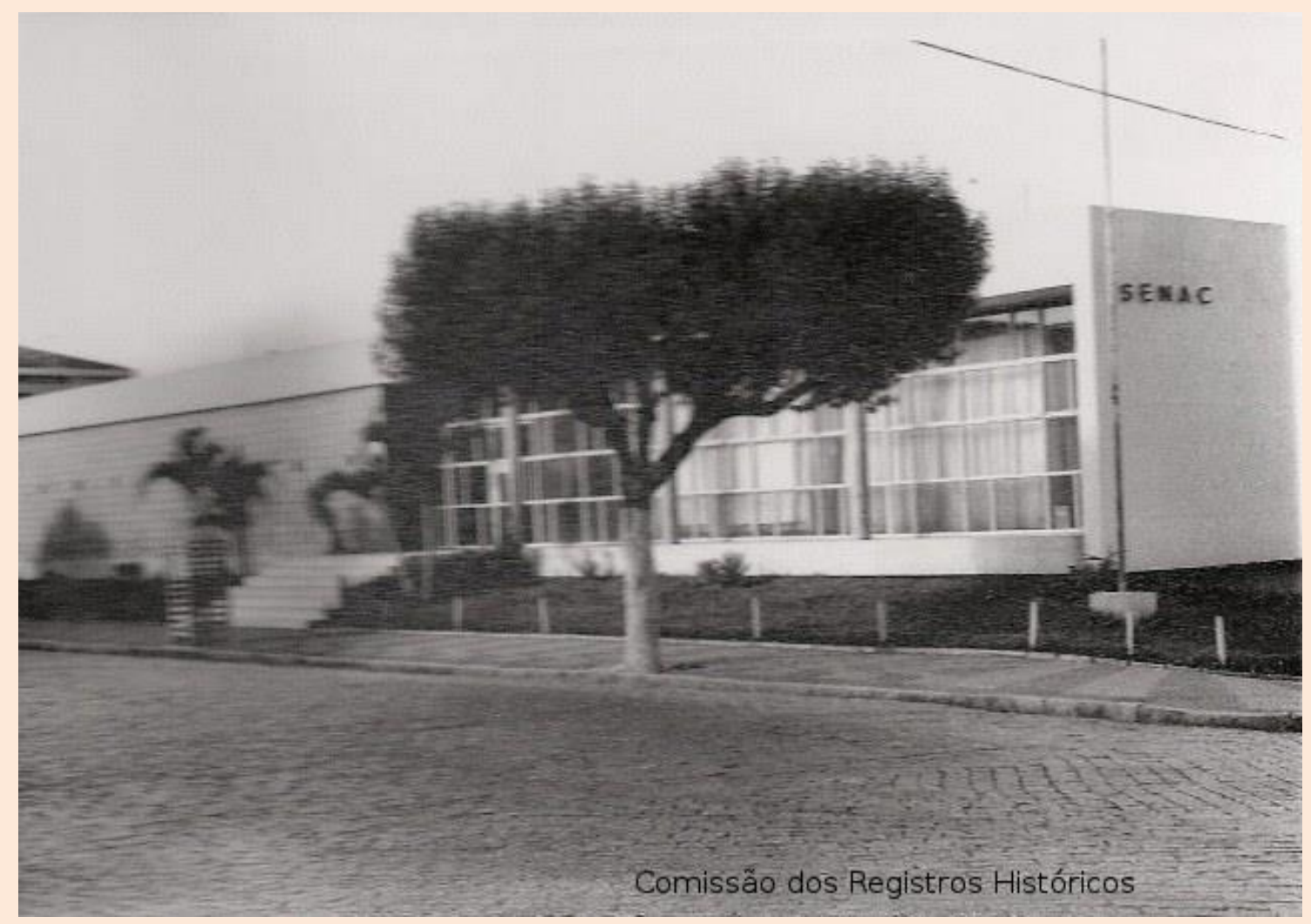

Figura 03: Escola SESC.SENAC em finais da década de 1950, Rua Nelson Spielmann.

Disponível: https://www.marilia.sp.leg.br/imprensa/galeria-de-fotos/registros-historicos/154; Acesso em: 03 fev. 2018.

É relevante salientarmos que houve apenas uma notícia do prédio escolar publicada pela imprensa local na década de 1990. O jornal Diário de Marília, em texto que destacou o início dos estudos sobre o tombamento do imóvel: "(..). A comunicação foí feita pelo Presidente do órgão, Edgard de Assis Carvalho, via ofício, ao Prefeito Domingos Alcade. Agora o SENAC não poderá intervir no prédio (...) sem a devida autorização" 17

Ressaltamos que essa notícia foi publicada na seção Cidade, com pequena chamada na capa do jornal, e, esse texto não apresentou nenhuma imagem da Escola SENAC, como não deu destaque na diagramação do periódico. No texto, o autor apenas relatou a abertura do processo de estudo de tombamento no Condephaat à imprensa de Marília, para ciência dos interessados, do início dos estudos de proteção oficial para a Prefeitura Municipal, por isso, sua publicação na imprensa.

No final de 2004, após quatorze anos de ausência na imprensa local, outra reportagem dessa instituição escolar foi publicada. Nela, o autor abordou a visita dos

17 Diário de Marília. Prédio do SENAC será preservado, 15/08/1990, p. 04. 
integrantes do Conselho Municipal de Cultura de Marília no edifício. Nesse evento, - imóvel foi entendido pelos membros desse conselho municipal como um exemplo de conservação arquitetônica, e, enfatizou-se a necessidade de um debate público sobre os bens protegidos oficialmente pelo Condephaat em Marília ${ }^{18}$.

Um dos pontos importantes nessa notícia é a tentativa dos membros do Conselho Municipal de Cultura, de acordo com a presidente, a professora Wânia Lombardi, que a sociedade de Marília conheça os detalhes da figura jurídica do tombamento: "Muita gente conhece o edifício, mas nunca se pensou que é tombado e as características históricas foram mantidas. Parece um prédio escolar comum, mas é um prédio que tem influência na história de nossa cidade, falou" ${ }^{19}$

Nessa reportagem, a autora salientou um dos principais problemas relativos ao patrimônio no Oeste Paulista: o desconhecimento da sociedade local, e o consequente desinteresse, se o imóvel foi tombado ou não e o que isso significa, entre outros assuntos correlatos

É necessário ressaltar que a análise dos jornais locais permitirá uma visão mais detalhada sobre os embates políticos e a construção de bens simbólicos:

O jornal local mantém vínculos com seus leitores que os grandes jornais não conseguem estabelecer. Por estar próxima do leitor e oferecer aquilo que interessa para o seu dia a dia, às vezes numa linguagem acentuada por significados regionalistas, a imprensa local permite ao cidadão participar do desenvolvimento de seu município, reclamar de falhas do poder público, exigirem direitos. O jornal faz parte da vida comunitária da cidade ${ }^{20}$.

Em seguida, o texto intitulado "O 'modernismo' no SENAC", de autoria de Rosalina Tanuri (professora aposentada, representante da Comissão dos Registros Históricos), destacou a presença desse imóvel no espaço urbano de Marília, como um símbolo da chegada da modernidade ao interior paulista

A autora comemorou o tombamento em âmbito estadual, e, exaltou a construção de um prédio que segue os princípios da arquitetura moderna em

18 Diário de Marília. Prédio do SENAC é modelo de preservação histórica, 30/11/2004.

${ }^{19}$ Diário de Marília. Op. Cit.

20 PEREIRA, Taís Assunção Curi. Imprensa do interior paulista: evolução e perspectivas para o Século XXI: o caso dos jornais centenários 'A Tribuna' e 'A Tribuna do Norte'. Dissertação (Mestrado em Ciências da Comunicação). SP: USP, 2000, p. 43. 
Marília, de autoria do engenheiro-arquiteto Oswaldo Correia Gonçalves: "Elegante, absolutamente cômodo, acolhedor, situado no coração da cidade, o SENAC é um dos primeiros presentes da Modernidade para Marília" ${ }^{21}$.

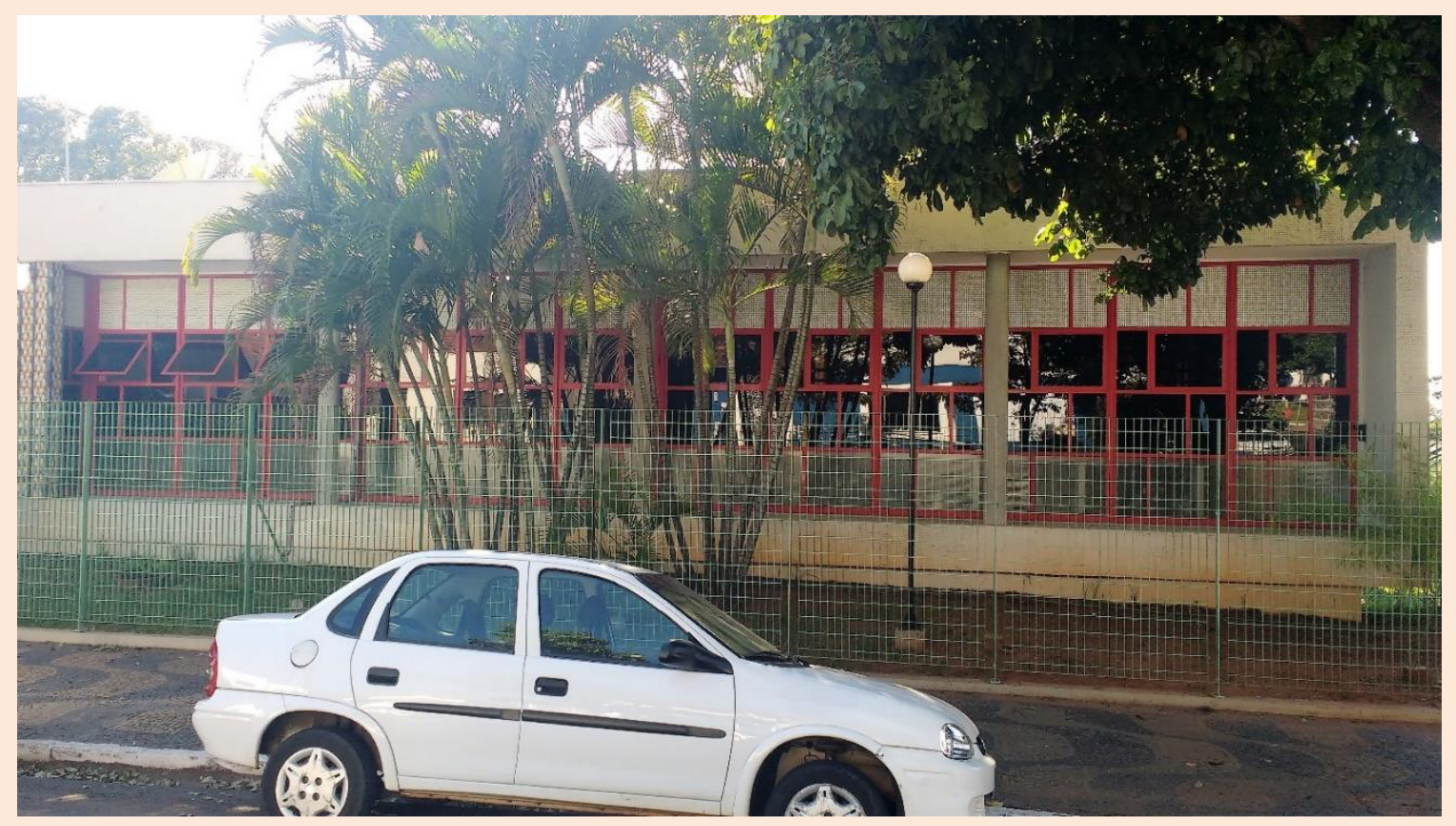

Figura 04: Fotografia atual da fachada da Rua Nelson Spielmann, com mudanças na estrutura física, em relação ao edifício de finais da década de 1950 (Figura 03). Autor: Rodrigo Modesto Nascimento, 2016.

Ana Luiza Martins, no estudo de tombamento realizado pelo Condephaat, notou o fato da imprensa de Marília não apresentar interesse em publicar textos da Escola SENAC: "Obra talvez hermética para o entendimento de seus contemporâneos, razão pela qual pouco noticiada nos periódicos, porém de valor permanente no quadro da arquitetura local" 22 .

As duas últimas notícias publicadas nesse periódico (Prédio do SENAC é modelo de preservação histórica e $O$ "modernismo" no SENAC, ambas publicadas no Diário de Marília, em 2004) foram resultado dos esforços de agentes sociais locais engajados nas questões culturais de Marília. Quem são esses agentes sociais? Membros do Conselho Municipal de Cultura e da Comissão dos Registros

21 Diário de Marília. O 'modernismo' no SENAC, 12/12/2004.

22 Processo de Tombamento n. 27.945/90, p. 195. 
Históricos, que contou com a anuência do referido periódico em publicar matérias de cunho cultural.

No mês de março de 2011, o jornal Diário de Marília publicou uma reportagem sobre as comemorações dos 60 anos do SENAC em que enfatizou temas relacionados ao ensino profissional. Mas em nenhum momento o autor da notícia fez qualquer alusão ao tombamento do prédio ${ }^{23}$.

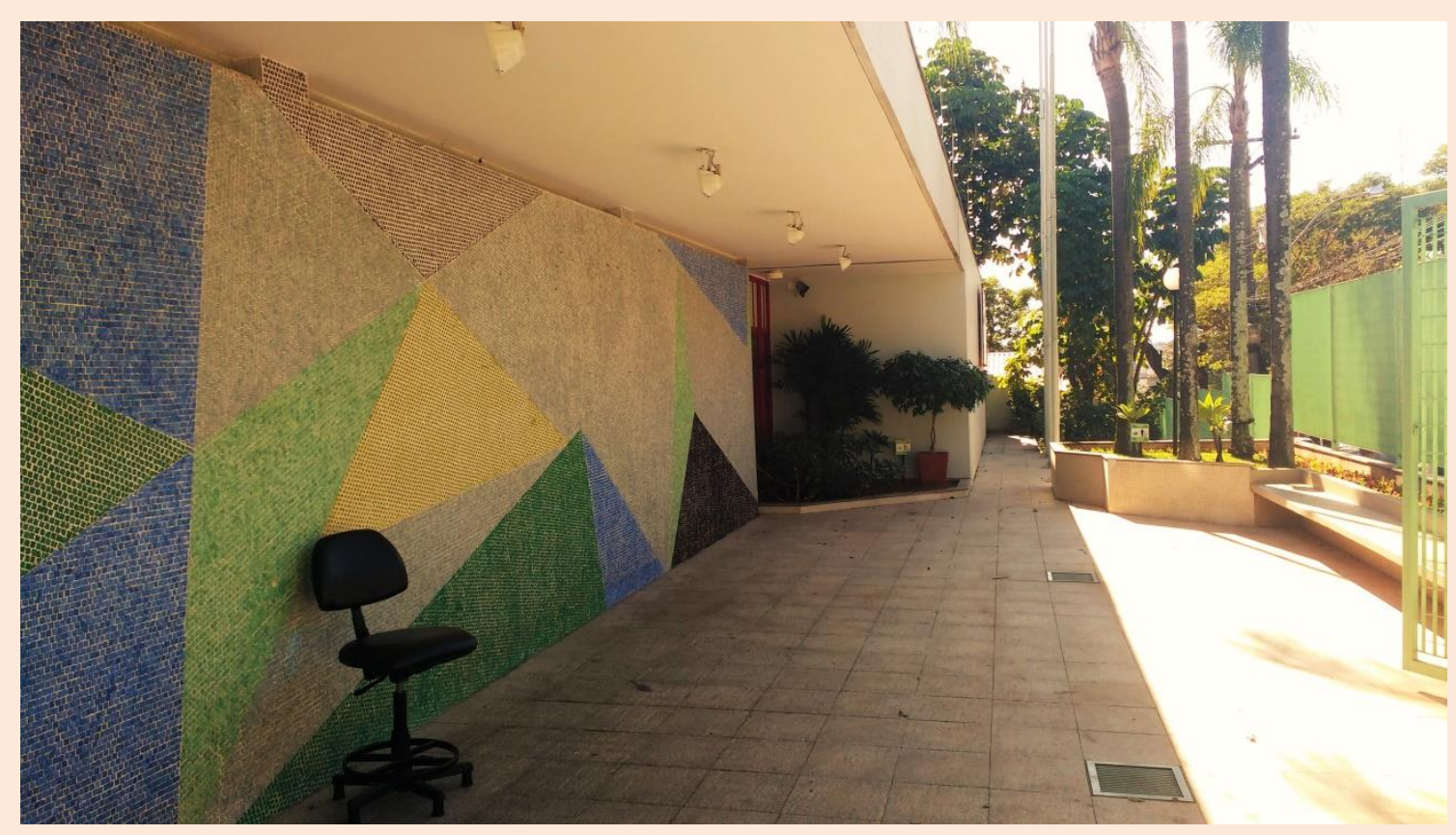

Figura 05: Pastilhas de vidro em painel mural, na entrada principal da unidade escolar. Arte realizada por Marcelo Grassman. Autor: Rodrigo Modesto Nascimento, 2016.

A única notícia publicada nesse ano, divulgada no jornal Correio Mariliense que diz respeito à Escola SENAC, novamente, as comemorações do aniversário do prédio, apresentou sua trajetória: "No dia primeiro de março de 1951, Marília ganhava uma das unidades do SENAC (...). Anos mais tarde, em 1958, foi inaugurado o prédio próprio, localizado na Rua Paraíba, 125 "24.

Com isso, na comemoração dos 60 anos do SENAC em Marília (em 2011), os autores dos dois textos publicados na imprensa (Correio Mariliense e Diário de

${ }^{23}$ Diário de Marília. SENAC - 60 anos faz programação especial, 06/03/2011.

${ }^{24}$ Correio Mariliense. SENAC chega aos 60 anos com a tradição de formar profissionais, 01/03/2011. 
Marília), não comentaram uma linha sequer sobre a proteção oficial da edificação e suas características arquitetônicas.

Isso nos mostra que o ato final de tombamento em 2005, com a inscrição no Livro do Tombo Histórico, não representou nenhuma importância para os responsáveis pela instituição educacional ou mesmo para a imprensa local em divulgarem a condição de bem cultural tombado pelo Estado de São Paulo, como um dos símbolos da arquitetura moderna.

\section{considerações}

Os membros da Comissão dos Registros Históricos realizaram apenas dois debates sobre a proteção oficial do SENAC, documentado em suas atas, na década de 1990, na busca de informações do andamento dos estudos em nível estadual. A valorização da arquitetura moderna, ressaltada no pedido não apareceu no discurso da Comissão dos Registros Históricos como um item fundamental para a proteção da edificação escolar.

$\mathrm{Na}$ imprensa local foram publicadas somente cinco notícias relativas a esse imóvel em catorze quatro anos. O conteúdo dessas matérias jornalísticas pautou-se por apresentar a sociedade de Marília à importância do edifício escolar, compreendido como um símbolo da modernidade. Ou seja, existe o valor da Escola SENAC para alguns setores da sociedade local, como observamos, mas uma negligência quanto a sua concepção arquitetônica.

A solicitação de tombamento partiu do Instituto dos Arquitetos do Brasil, e assim, refletiram-se na pouca discussão observada nas fontes históricas produzidas em Marília, e, com isso, não apresentou os valores e as concepções locais da Escola SENAC, que certamente, seriam outras

Ressaltamos que a preservação de edificaçães novas, como a Escola SENAC, construída em 1958 e, tombada no ano de 2004, é considerada um dos principais entraves ao reconhecimento dos exemplares de arquitetura moderna como patrimônio cultural, tanto no Brasil como no exterior ${ }^{25}$.

Então, para quem esse edifício escolar foi preservado?

\footnotetext{
25 Ver esse tema e outros relativos aos tombamentos pelo IPHAN, da arquitetura modernista como patrimônio cultural, na pesquisa de Carolina Dal Ben Pádua: Arquitetura moderna: um estudo sobre patrimônio e preservação. Dissertação (Mestrado em Arquitetura e Urbanismo). SP: USP, 2013.
} 
Para os grupos sociais que conseguem fazer uma leitura da sua arquitetura, exemplo da volumetria compacta, da laje plana, das artes plásticas e das linhas retas, como os arquitetos e estudantes de arquitetura, professores de arte, entre outros especialistas. E, também, para os grupos vinculados ao campo cultural local, membros da Comissão dos Registros Históricos e do Conselho Municipal de Cultura, mesmo sem valorizar os princípios da arquitetura modernista.

É necessário ressaltar que a inclusão da Educação Patrimonial nas escolas de educação básica, em especial, no currículo das disciplinas de História ou Arte e, assim, a escola poderia contribuir para a valorização e o reconhecimento de diversas edificações que passam despercebidas, em muitas cidades do interior paulista e do Brasil, mas que possuem relevância para a História da Arquitetura. 